\title{
Aspects of petroleum hydrocarbon metabolism in marine animals
}

\author{
O. G. Mironov \\ Institute of Biology of South Seas; 2 Nahimov Avenue, Sevastopol, USSR
}

\begin{abstract}
Studies on hydrocarbon composition of Black Sea mussels Mytilus galloprovincialis sampled from different habitats indicate that the quantity and composition of hydrocarbons distributed in the molluscs depend on season and sea-water quality. The data obtained under experimental conditions testify to the possibility of hydrocarbon concentration in mussel tissues after death. During filtration in sea water containing oil and oil products, these pollutants are bound into faeces and pseudofaeces which contain a greater percentage of aromatic compounds than the oil initially present in sea water. Quantitative data are presented on hydrocarbon changes in mussel excretory products during transfer from oil-polluted to clean sea water. When Black Sea crabs Eriphia verrucosa are fed with mussels containing fuel-oil components accumulated from sea water, the pollutants concentrate in the whole body of the crab. This is in contrast to parenteral oil uptake, which leads to a concentration of most of the hydrocarbon in the muscles.
\end{abstract}

\section{INTRODUCTION}

The biological role of hydrocarbons and their composition in marine organisms have received little attention. Some researchers noted the hydrocarbon composition of hydrobionts changed as a function of growth (Blumer et al., 1969) or food source. Thus, mussels Mytilus edulis showed quantitative and qualitative differences in hydrocarbon composition before and after phytoplankton blooms. Hydrocarbon composition may be used as taxonomic indicator (Youngblood et al., 1971). Hydrocarbons are considered to be stable chemical substances which may pass unchanged through the food chain (from prey to predator). For example, zooplankton pristane passes the intestine of a shark without fractionation and structural alterations when accumulated in the liver (Blumer, 1967). Hydrocarbons may be formed from compounds taken up with food. An example is the formation of pristane from phytol and phytoplankters in some zooplankton species.

In recent years these processes have been studied against the background of marine pollution and involvement of oil components in the hydrocarbon exchange of organisms. A number of authors consider that petroleum hydrocarbons may be accumulated in significant quantities in organisms and remain there during the entire life of the organisms (Lee et al., 1972; Stegeman \& Teal, 1973).

In this context, investigations on hydrocarbon content in marine organisms as well as processes of accumulation and elimination of petroleum hydrocarbons - both during life and post-mortem transformations are of theoretical and practical interest. 


\section{MATERIAL AND METHODS}

We consider here information obtained in the Marine Sanitary Hydrobiology Department (Institute of Biology of South Seas, Sevastopol, USSR). The methods employed are based on procedures described by Mironov \& Shchekaturina (1977). Mussels Mytilus galloprovincialis were sampled in two bays of the Black Sea and treated immediately after sampling. Their body sizes varied between 35 and $65 \mathrm{~mm}$ (average: 55 $\mathrm{mm}$ ). The soft parts were separated from the shell, dried on filter paper in 100-g portions and homogenized. Lipids were extracted with a mixture of $\mathrm{CCl}_{4}$ and methanol (2:1). Hydrocarbon separation from lipids was performed in a column $2.5 \times 70 \mathrm{~cm}$ packed with silicagel ASK, activated at $155^{\circ} \mathrm{C}$. The ratio organic substance to adsorbent was 1:50. The hydrocarbon fraction was washed with $400 \mathrm{ml}$ of hexane. The isolated hydrocarbons were then identified with a chromatograph CHROM-3. A nozzle column of 1.2-m length, 0.6-cm diameter, packed with Chesacorb MV-HMDS $0.250-0.360$ mesh, silanated HMDS, soaked with $5 \%$ silicone SE-30 was used. The temperature in the injected chamber was $300^{\circ} \mathrm{C}$. Analysis programming was performed from $100^{\circ} \mathrm{C}$ to $270^{\circ} \mathrm{C}$, at the rate of $3{ }^{\circ} \mathrm{C} / \mathrm{min}$. Detector sensitivity was $1: 100$. In addition, microchromatographic analyses of hydrocarbon mixtures were carried out. These facilitated fractionation. Crabs Eriphia verrucosa were treated in the same way.

\section{RESULTS AND DISCUSSION}

Seasonal changes in the hydrocarbon content of Mytilus galloprovincialis are presented in Table 1. M. galloprovincialis were sampled from Black Sea aquatoria with different degrees of water pollution.

Table 1 illustrates that the total quantity of hydrocarbons contained in organisms from "Bay b" much exceeds that from "Bay a". Earlier data (Mironov, 1967) from the same aquatoria showed more intensive pollution by oil products of Bay $b$ than Bay a.

Increased amounts of hydrocarbon were noticed in mussels from "clean" waters in March and April. This might be linked with the phytoplankton bloom which attained its maximum in this area in March (Rouchijainen, 1975).

Table 2 represents quantitative characteristics of normal paraffins. The data indicate that the sum of $n$-paraffins in organisms from Bay b is 7 times higher than in those from Bay a.

Besides, in the analysed oily fractions from mussels sampled from polluted waters, aromatic and heterocyclic compounds were determined in quantities amounting to 13.03 and 17.0 weight percents, respectively. This is not typical of hydrocarbons in marine organisms (Farrington et al., 1973).

Table 1. Mytilus galloprovincialis. Qualitative changes in hydrocarbon contents of mussels from two Black Sea bays. All values expressed as $\mathrm{mg} / 100 \mathrm{~g}$ wet weight. $\mathrm{n} . \mathrm{d} .=$ not determined

\begin{tabular}{|crrrrrrrrr}
\hline Aquatoria & Dec. & Jan. & Feb. & March & April & May & June \\
1977 & 1978 & 1978 & 1978 & 1978 & 1978 & 1978 & $\begin{array}{r}\text { July } \\
1978\end{array}$ \\
\hline Bay a & 19.7 & 26.9 & 23.2 & 71.3 & 59.8 & 35.7 & 37.1 & 57.4 \\
Bay b & 199.4 & 228.2 & 177.6 & n.d. & 102.7 & 70.1 & n.d. & 100.0 \\
\hline
\end{tabular}


Table 2. Mytilus galloprovincialis. Normal paraffin contents in mussels sampled from different bays. All values expressed as $\mathrm{mg} / 100 \mathrm{~g}$ wet weight (after Mironov \& Shchekaturina, 1977)

\begin{tabular}{|ccc|}
\hline n-paraffins & Bay a & Bay b \\
\hline $\mathrm{C}_{12}$ & 0.08 & 0.30 \\
$\mathrm{C}_{14}$ & 0.40 & 3.00 \\
$\mathrm{C}_{15}$ & 0.24 & 1.50 \\
$\mathrm{C}_{16}$ & 1.56 & 4.50 \\
$\mathrm{C}_{17}$ & 0.28 & 2.50 \\
$\mathrm{C}_{18}$ & 0.20 & 2.25 \\
$\mathrm{C}_{19}$ & 0.56 & 7.00 \\
\hline Total & 3.32 & 21.05 \\
\hline
\end{tabular}

The given components (aromatic and heterocyclic) were not revealed in molluscs from the unpolluted bay.

The petroleum hydrocarbons accumulated in marine organisms may be eliminated during the life of the organisms or after death. Here we encounter the problem of hydrocarbon transformation into detritus.

Studies on decompositional dynamics of mussels (dissected mussels were placed in a sack made of dense plankton gauze submerged in running seawater; 40-day incubation) revealed that the amounts of hydrocarbons increased gradually from 79.1 to 134.6 $\mathrm{ng} / 100 \mathrm{~g}$ wet weight.

Aliphatic hydrocarbons undergo more complicated changes in the process of mussel decomposition and detritus formation. At first their total quantity drops by $17 \%$ and then on the 40th day increases by $96 \%$ compared with initial values.

During the dynamic changes in individual paraffins, the amount of " $n$-alkanes" decreases in the first 20 days. This may be explained by susceptibility to microflora oxidation.

During the following days, the amount of $n$-alkanes increases sharply. Probably, synthetic lipid processes predominate over decomposition processes. In addition, the amount of hydrocarbons may increase due to formation from fats and fatty acids.

Thus, hydrocarbons are relatively resistant to biodegradation during the process of mussel decomposition. At the same time hydrocarbon synthesis proceeds due to lipid decomposition. These two processes are of importance when evaluating anthropogenic pollution effects on marine basins, in particular, when studying the biogeochemical activities of organisms.

Of particular interest is the transformation of hydrocarbons by living marine organisms. When mussels filter sea water containing oil and oil products, the oil is bound into faeces and pseudofaeces. Bile salts and some other natural detergents are considered to be able to emulsify hydrocarbons and to allow them to pass via the gut into excretory products. Oysters may metabolize paraffins (Stegeman \& Teal, 1973).

Experiments with Black Sea mussels (Mironov \& Shchekaturina, 1979) show that faeces and pseudofaeces, collected while the mussels were exposed to oiled sea water, contain significant quantities of hydrocarbons ( 315.5 and $242 \mathrm{mg} / 100 \mathrm{~g}$ dry weight, respectively). Thus intensive filtration by the molluscs leads to the binding of oilpollution components. When such mussels are placed in clean sea water, elimination of 
hydrocarbons occurs from the body; the intensity of faeces and pseudofaeces production drops naturally with time.

The results show that oil concentration in pseudofaeces falls faster in the first 5 days (by a factor of 7); during the next 5 days its value remains more or less constant. By contrast, oil concentration in faeces decreased by 3 times in the first 5 days and more than 5 times during the next 5 days. This shows that natural elimination of accumulated hydrocarbons occurs mainly via the intestine.

The oil content in the test organisms is 2 to 4 times higher. This demonstrates that a 10-day presence of mussels in clean sea water (with background pollution) is not sufficient to eliminate the oil accumulated.

Analysis of hydrocarbon contents in oil and oil products revealed that faeces and pseudofaeces contain higher percentages of aromatic compounds than the oil initially introduced into the system. This fact may be associated with the greater solubility of aromatic hydrocarbons in sea water because they penetrate mussel tissue more easily.

Mussels may serve as food for other animals, for example, crabs. Eriphia verrucosa individuals were fed mussels which had accumulated diesel oil from sea water. Other crabs kept in running sea water with diesel oil concentration of approximately $20 \mathrm{mg} / 1$ were not fed during the experiment. Subsequently, hydrocarbons were determined in liver, gonads and the remaining body parts analysed as a whole (the latter portion will subsequently be referred to as "body").

Since no data on hydrocarbon content of Black Sea crabs were available, the content of hydrocarbons and their components in crab tissues was determined prior to the experiment. The hydrocarbon contents measured were: liver $234.6 \mathrm{mg} / 100 \mathrm{~g}$ wet weight, gonads 49.9, "body" 18.2 .

Thus, the crabs examined contained a certain quantity of petroleum hydrocarbons, and these were unequally distributed over different organs and tissues.

Table 3. Eriphia verrucosa. Hydrocarbons accumulated in crab organs. All values expressed as \% of the initial value

\begin{tabular}{|c|c|c|c|c|c|c|c|c|c|}
\hline \multirow[t]{2}{*}{ Test } & \multicolumn{3}{|c|}{ Methanonaphthenic } & \multicolumn{3}{|c|}{ Aromatic } & \multicolumn{3}{|c|}{ Hetero-atomic } \\
\hline & Body & Liver & Gonads & Body & Liver & Gonads & Body & Liver & Gonads \\
\hline $\mathbf{I}^{*}$ & 59.0 & 0 & 151.0 & 51.0 & 45.0 & 575.0 & 102.0 & 378.0 & 0 \\
\hline $\mathrm{II}^{* *}$ & 89.0 & 139.0 & 40.0 & 5.0 & $\mathbf{0}$ & 0 & 0 & 273.0 & 0 \\
\hline
\end{tabular}

Table 3 lists the results of the experiment and shows differential tendencies of hydrocarbon accumulation. Methanonaphthenic hydrocarbons prevail in body and gonads of crabs exposed to diesel oil. In crabs fed polluted mussels for 10 days, accumulation of methanonaphthenic hydrocarbons occurs in all organs. Hydrocarbons, passing with the food taken up via the intestine, are accumulated in the whole body, first of all in the fat-rich liver. Here the highest accumulation percentage was recorded as compared with other organs. 
Accumulation of aromatic and heterocyclic compounds was noticed in almost all organs of animals exposed to water with diesel oil. However, in crabs fed polluted mussels, accumulation of these hydrocarbons practically did not occur. The same result was obtained by Funasaka et al. (1975).

Hence, in Mytilus galloprovincialis we attempted to investigate possible pathways of hydrocarbon transformation: for example, changes in hydrocarbon content of individuals in differently polluted aquatoria; hydrocarbon changes during filtration, as well as during post-mortem decomposition; transfer of hydrocarbons accumulated by mussels through the food web.

Compared with the situation in microorganisms, where the role of biodegradation is well elucidated, biodegradation in other hydrobionts requires more detailed experimental analysis (for review consult Sorokin, 1978). This appears to be primarily due to methodological difficulties.

\section{LITERATURE CITED}

Blumer, M., Robertson, J. C., Gordon, J. E. \& Sass, J., 1969. Phytol-derived C ${ }_{19}$ di- and tri-olefinic hydrocarbons in marine zooplankton and fishes. - Biochem. 8, (4067), 74.

Ehrhardt, M. \& Heinemann, J., 1974. Hydrocarbons in blue mussels from the Kiel Bight. - Spec. Publs U. S. natn. Bur. Stand. 409, 221-225.

Farrington, J. W., Teal, J. M., Quinn, J. G., Wade, T. \& Burns, K., 1973. Intercalibration of recently biosynthesized hydrocarbons and petroleum hydrocarbons in marine lipids. - Bull. environ. Contam. Toxicol. 10, 129-136.

Fossato, V. U., 1975. Elimination of hydrocarbons by mussels. - Mar. Pollut. Bull. 6, 7-10.

Funasaka, R., Ore, Y. \& Sato, T., 1975. Aromatic hydrocarbons as one from many unpleasantlysmelling compounds. - J. Hyd. Chem. 21, 93-100.

Koons, C. B., Jamieson, G. W. \& Cicroszko, L. S., 1965. Normal alkane distribution of marine origin. - Bull. Am. Ass. Petrol. Geol. 49, 301-304.

Mironov, O. G., 1967. On pollution of Black Sea waters by oil products. In: Dinamika vod i voprosi gidrohimii Chernogo morya. Ed. by V. A. Vodyanitskiy. Naukova Dumka, Kiev, 127-133.

Mironov, O. G. \& Shchekaturina, T. L., 1977. Hydrocarbons in marine organisms. - Gidrobiol. Zh. $12,(6), 5-15$.

Mironov, O. G. \& Shchekaturina, T. L., 1979. Oil change in mussel Mytilus galloprovincialis excretion. - Mar. Pollut. Bull. 10, 232-234.

Rouchijainen, M. I., 1975. On seasonal dynamics of Black Sea phytoplankton. - Biol. Moria, Kiev 34, 3-25.

Sorokin, Yu. I., 1978. Decomposition of organic matter and nutrient regeneration. In: Marine ecology. Ed. by O. Kinne. Wiley-Interscience, Chichester, 4, 501-616.

Stegeman, J. J. \& Teal, J. T., 1973. Accumulation, release and retention of petroleum hydrocarbons by the oyster Crassostrea virginica. - Mar. Biol. 22, 37-44. 